\title{
Countergradient heat flux observations during the evening transition period
}

\author{
E. Blay-Carreras ${ }^{1}$, E. R. Pardyjak ${ }^{2}$, D. Pino ${ }^{1,3}$, D. C. Alexander ${ }^{2}$, F. Lohou ${ }^{4}$, and M. Lothon ${ }^{4}$ \\ ${ }^{1}$ Department of Applied Physics, Universitat Politècnica de Catalunya, BarcelonaTech, Barcelona, Spain \\ ${ }^{2}$ Department of Mechanical Engineering, University of Utah, Salt Lake City, UT, USA \\ ${ }^{3}$ Institute of Space Studies of Catalonia (IEEC-UPC), Barcelona, Spain \\ ${ }^{4}$ Université de Toulouse - CNRS 5560, Laboratoire d'Aérologie, Toulouse, France \\ Correspondence to: E. Blay-Carreras (estel.blay@upc.edu)
}

Received: 4 March 2014 - Published in Atmos. Chem. Phys. Discuss.: 21 March 2014

Revised: 30 June 2014 - Accepted: 8 July 2014 - Published: 3 September 2014

\begin{abstract}
Gradient-based turbulence models generally assume that the buoyancy flux ceases to introduce heat into the surface layer of the atmospheric boundary layer in temporal consonance with the gradient of the local virtual potential temperature. Here, we hypothesize that during the evening transition a delay exists between the instant when the buoyancy flux goes to zero and the time when the local gradient of the virtual potential temperature indicates a sign change. This phenomenon is studied using a range of data collected over several intensive observational periods (IOPs) during the Boundary Layer Late Afternoon and Sunset Turbulence field campaign conducted in Lannemezan, France. The focus is mainly on the lower part of the surface layer using a tower instrumented with high-speed temperature and velocity sensors.

The results from this work confirm and quantify a fluxgradient delay. Specifically, the observed values of the delay are $\sim 30-80 \mathrm{~min}$. The existence of the delay and its duration can be explained by considering the convective timescale and the competition of forces associated with the classical Rayleigh-Bénard problem. This combined theory predicts that the last eddy formed while the sensible heat flux changes sign during the evening transition should produce a delay. It appears that this last eddy is decelerated through the action of turbulent momentum and thermal diffusivities, and that the delay is related to the convective turnover timescale. Observations indicate that as horizontal shear becomes more important, the delay time apparently increases to values greater than the convective turnover timescale.
\end{abstract}

\section{Introduction}

The general behavior of the diurnal cycle of the atmospheric boundary layer (ABL) under clear sky fair weather conditions is well-known (Stull, 1988). During the day, a convective boundary layer driven by surface and entrainment fluxes exists (Moeng and Sullivan, 1994; Sorbjan, 1996; Sullivan et al., 1998; Pino et al., 2003; Fedorovich et al., 2001). Late in the afternoon, due to radiative cooling of the ground, a stable boundary layer (SBL), where turbulence may be suppressed, is created adjacent to earth's surface (Nieuwstadt, 1984; Mahrt, 1998; Beare et al., 2006). A residual layer (RL) of weak turbulence exists above this SBL. The RL occupies a similar space as the mixed layer of that day's convective boundary layer (CBL). However, the details of certain processes, particularly those associated with nonstationary transitional periods, are not as well understood. The transition occurring after the peak in solar insulation can be divided into two distinct periods: the afternoon transition, when the surface sensible heat flux starts to decrease from its midday maximum, and the evening transition, when the surface sensible heat flux becomes negative (Nadeau et al., 2011).

This paper focuses on the behavior of the buoyancy flux and temperature gradient in the surface layer during the evening transition period by analyzing measurements obtained during the Boundary Layer Late Afternoon and Sunset Turbulence (BLLAST; Lothon et al., 2014) field campaign. BLLAST was conceived to study the late afternoon transition (LAT) processes in the ABL. Objectives of the BLLAST project include gaining a better understanding of 
(a) the importance of surface heterogeneity on the LAT and (b) the structure and evolution of the boundary layer itself during this period of the day. The team members of this project include an international group of scientists from different European countries and the USA. The main hypotheses to be tested during this study are focused on the afternoon transition; therefore, the observations obtained from the BLLAST campaign provide a valuable framework to develop the present work.

In this work, we hypothesize that during the evening transition, a delay exists between the instant when the buoyancy flux goes to zero and the time when the local gradient of the virtual potential temperature indicates a sign change. While this hypothesis has received little attention during the transition period, Ghan (1981) and Franchitto and Rao (2003) attempted to find a relationship between the temperature gradient and the heat flux, considering the complete diurnal cycle. In addition, nonlocal modeling studies have been used to develop different theories about eddy diffusivity and countergradient transport (Deardorff, 1972; Holtslag and Moeng, 1991). Holtslag and Boville (1993) introduced a nonlocal term in the parameterization of vertical diffusion in the atmospheric boundary layer to account for convective situations where the heat flux can be counter to the local potential temperature gradient (positive heat flux and positive gradient of potential temperature). In this case, turbulence results from nonlocal transport by eddies on the order of the size of the boundary layer. This mainly occurs at the upper part of the boundary layer, just below the entrainment zone and far from the surface layer.

Investigations using observations (Grimsdell and Angevine, 2002) or large-eddy simulations (Nieuwstadt and Brost, 1986; Sorbjan, 1997; Pino et al., 2006) have shown that entrainment fluxes introduce heat in the boundary layer after the sensible heat flux becomes negative, producing turbulence in the middle of the mixed layer several hours after sunset (demixing process). However, Darbieu et al. (2014) have recently shown, using LES (large-eddy simulations) and aircraft observations during the afternoon transition, that turbulence (TKE and variances) decreases earlier in the upper levels of the boundary layer. If this result is also true during the evening transition, it seems that demixing, if it exists, cannot also be attributed to entrainment. Again, none of these studies focused on the response of the surface layer during this transition.

At the surface layer, it is normally assumed that the buoyancy flux ceases to introduce heat into the ABL at the same instant that the gradient of the virtual potential temperature reflects this phenomenon. Most simulation models work using this basic concept. A good knowledge of the phenomenon and evolution of the afternoon/evening transition is crucial for developing more realistic models and creating better approximations (Sorbjan, 1997; Cole and Fernando, 1998; Edwards et al., 2006; Pino et al., 2006; Angevine, 2007; Nadeau et al., 2011).
The objective of this article is to investigate this phenomenon using a range of data collected over several days, focusing mainly on the lower surface layer, using a tower instrumented with fast response fine-wire (FW) thermocouples and sonic anemometers/thermometers (SATs). Moreover, the hypothesis will be supported by theories that can explain this phenomenon, such as the inverse Bénard problem, the effect of convective time or the definition of convection characteristics with the help of the Monin-Obukhov length scale.

The paper is structured as follows. In Sect. 2, we present the theory supporting the main hypothesis of the article. In Sect. 3, we describe the BLLAST field campaign and the instruments selected to test the hypothesis including the method for identifying time periods of interest for the analysis. In Sect. 4, we present the results focusing on the delay and convective time analysis, the Monin-Obukhov lengthscale analysis and turbulent Rayleigh number analysis. Finally, Sect. 5 summarizes the results.

\section{Background theory}

The hypothesis, which was described in the introduction, can be related to the well-known Rayleigh-Bénard (R-B) problem (thermal instability) associated with the heating of a quiescent layer of fluid from below, which ultimately results in turbulent free convection (Kundu and Cohen, 2010). The standard R-B problem is based on the idea that there is a layer of fluid heated from below, however, the upper part of the layer is heavy enough to stifle the convective movements. Both viscosity and thermal diffusivity make it difficult for convection movements to happen. Therefore, large temperature gradients are required to create the instability that makes movement possible. Here we consider similar physics, but in the opposite sense because during LAT the CBL is cooled from below. The idea was previously introduced and experimentally studied by Cole and Fernando (1998), who designed a laboratory water tank experiment to observe the decay of temperature and velocity fluctuations in the CBL in response to cooling the surface.

In both the classical R-B problem and the phenomena studied in this paper, a delay exists that is related with the buoyancy flux at the surface and convective movements. When the buoyancy flux ceases, the convective movements continue for some time. This delay can be similarly produced from the same factors that drive the classical R-B problem. In other words, the viscosity and the thermal diffusivity make it possible for this transition to happen in a smoother way. The dimensionless parameter, which compares the destabilizing forces (buoyancy forces) with the stabilizing forces (viscosity and thermal diffusivity) is the Rayleigh number,

$R a=\frac{g \Delta \overline{\theta_{\mathrm{v}}}(\Delta z)^{3}}{\overline{\theta_{\mathrm{v}}} \kappa v}$ 
where $g$ is the gravitational constant, $\Delta \overline{\theta_{\mathrm{v}}}$ is the average virtual potential temperature difference over the layer depth $\Delta z$ (taken here as the height of the atmospheric near-surface layer), $\kappa$ is the molecular thermal diffusivity and $v$ is the molecular kinematic viscosity. For the classical R-B problem with heating from below, when the Rayleigh number reaches a critical value, $R a_{\mathrm{cr}}$, convective movement will start. In this paper, we provide preliminary evidence for a transitional turbulent Rayleigh number at which convective motions cease.

\section{Methodology}

This study was performed within the framework of the BLLAST field campaign. Amongst the wide range of instruments deployed during the campaign, a relatively short $(10 \mathrm{~m})$, but highly instrumented tower was selected to be used in this study. This tower, located at $43^{\circ} 07^{\prime} 39.3^{\prime \prime} \mathrm{N}$, $00^{\circ} 21^{\prime} 57.9^{\prime \prime} \mathrm{E}$ was selected because it was equipped with a large number of closely spaced sensors, and was placed over relatively simple and homogeneous terrain (flat grass field). The sensors deployed on the tower included SATs and FWs. The instrument-deployment strategy focused many sensors close to the ground in order to observe small and fast changes connected to this zone. Figure 1a shows the vertical location of the instruments on the $10 \mathrm{~m}$ mast and Fig. 1b shows an aerial view of the site where the tower was located.

Four Campbell Scientific sonic anemometer thermometers (CSAT3, Logan, UT) fitted with $12.7 \mu$ m diameter Campbell Scientific E-TYPE model FW05 fine-wire thermocouples were mounted at the following heights: $2.23,3.23,5.27$ and $8.22 \mathrm{~m}$ above ground. Closer to the ground, there were four additional FW05 sensors mounted at 0.091, 0.131, 0.191, and $0.569 \mathrm{~m}$ above ground. These small diameter thermocouples were selected to minimize solar loading and response time to turbulent temperature fluctuations. The lowest sensor was placed just in the grass canopy. The grass around this sensor was regularly trimmed to maintain a canopy height of approximately $7-9 \mathrm{~cm}$. During the intensive observation periods (IOPs) the lowest FWs were installed during the afternoon through the entire transition period to provide an expanded data set. All instruments recorded data at $20 \mathrm{~Hz}$. However, 5 min block-averaged data are presented in the analysis shown below. All data were processed using the software package ECPACK (Van Dijk et al., 1998).

This study focuses on the analysis of the following group of IOP days during the BLLAST campaign: 24, 25, 27, 30 June and 1, 2 July 2011. These IOPs represent days when the $10 \mathrm{~m}$ tower was completely instrumented. Table 1 summarizes the information used to characterize the IOPs including the daily maximum surface sensible heat flux, the duration of the diurnal cycle and the days since the last rainfall.

The primary goal of this work is to characterize and understand the observed time delay between the instant when the buoyancy flux is zero and when the virtual potential temper-
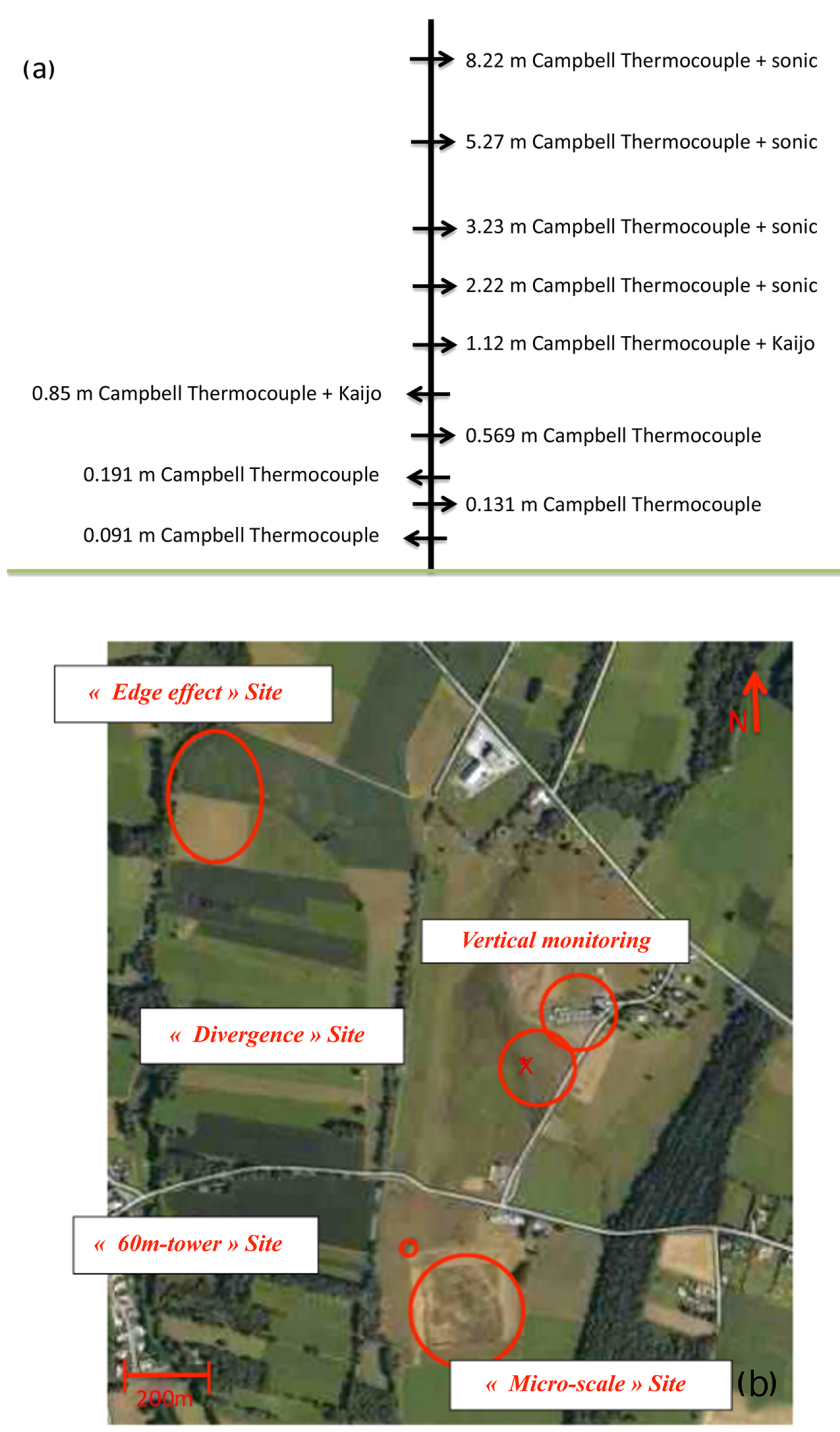

Figure 1. (a) Sketch of the distribution of sensors that were deployed on the $10 \mathrm{~m}$ mast during BLLAST and (b) an aerial view of the site (the red $\mathrm{X}$ indicates the location of the $10 \mathrm{~m}$ tower).

ature gradient changes sign. To sketch the change of sign of the gradient of virtual potential temperature, Fig. 2 shows the temporal evolution of the vertical profile of potential temperature measured by the FWs located on the $10 \mathrm{~m}$ mast during the evening of 1 July 2011. We can observe how, at the lowest levels, the gradient of potential temperature changes sign from negative to positive.

The instrumentation used in the campaign included fewer SATs than FW thermocouples, so the instruments were not always collocated. However, to include the effects of humidity, we use the measurements made by the SATs located at 2.23 and $3.23 \mathrm{~m}$ because these are the lowest sensors which can be used to simultaneously measure virtual potential temperature gradients and buoyancy flux. 
Table 1. Based on the observations taken during the BLLAST campaign, IOP day, maximum sensible heat flux $\left(\mathrm{SH}_{\mathrm{max}}\right)$, length of the day, days since last rainfall, delay time, convective timescale, convective intensity, transitional turbulent Rayleigh number and temporal difference between the time when $R a$ and buoyancy flux change sign.

\begin{tabular}{|c|c|c|c|c|c|c|c|c|c|c|}
\hline $\begin{array}{l}\text { Day } \\
\text { (IOP) }\end{array}$ & $\begin{array}{l}\mathrm{SH}_{\max } \\
\left(\mathrm{Wm}^{-2}\right)\end{array}$ & $\begin{array}{l}\text { Diurnal cycle } \\
\text { (h) }\end{array}$ & $\begin{array}{l}\text { Sunset } \\
\text { (UTC) }\end{array}$ & $\begin{array}{l}\text { Days since } \\
\text { last rainfall }\end{array}$ & $\begin{array}{c}\text { DT } \\
(\min )\end{array}$ & $\begin{array}{l}t_{*} \\
(\min )\end{array}$ & $-z / L$ & $\begin{array}{l}\text { Convective } \\
\text { intensity }\end{array}$ & $R a_{\mathrm{t}}$ & $\begin{array}{c}R a_{\mathrm{t}}-\mathrm{BF} \\
\quad(\min )\end{array}$ \\
\hline 24 June (IOP4) & 0.18 & 13.3 & $19: 42$ & 1 & 38 & 36 & 0.297 & Convective & 9.89 & 49 \\
\hline 25 June (IOP5) & 0.158 & 12.8 & $19: 42$ & 2 & 48 & 26.37 & 0.102 & Weak & 1.097 & 90 \\
\hline 27 June (IOP7) & 0.1 & 10.25 & $19: 42$ & 4 & 72 & 42 & 0.1205 & Weak & 3.62 & 95 \\
\hline 30 June (IOP8) & 0.11 & 12.16 & $19: 42$ & 1 & 30 & 27 & 0.289 & Convective & 10.32 & 34 \\
\hline 1 July (IOP9) & 0.138 & 12.8 & $19: 41$ & 2 & 40 & 33 & 0.22 & Moderate & 5.01 & 55 \\
\hline 2 July (IOP10) & 0.14 & 11.3 & $19: 41$ & 3 & 42 & 55.8 & 0.24 & Moderate & 4.5 & 53 \\
\hline
\end{tabular}

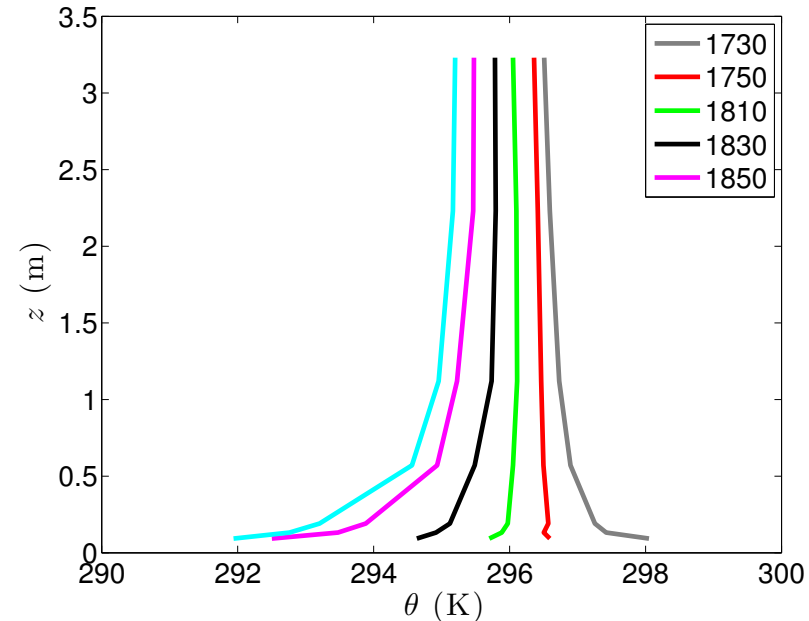

Figure 2. Observed 5 min averaged vertical profile of potential temperature during the evening transition on 1 July 2011.

To estimate the virtual potential temperature $\left(\theta_{\mathrm{v}}\right)$, we assumed that the virtual temperature $\left(T_{\mathrm{v}}\right)$ can be approximated by the sonic temperature. The virtual potential temperature was then estimated using the adiabatic lapse rate $(\Gamma)$ as follows: $\theta_{\mathrm{v}}=T_{\mathrm{v}}+\Gamma z$. Gradients were then computed using finite differences (Chapra and Canale, 1998).

The following paragraphs describe how this delay is determined. Figure 3 shows the observed temporal evolution of $\theta_{\mathrm{v}}$ at 2.23 and $3.23 \mathrm{~m}$ during two IOPs and illustrates the time when the change in sign of the gradient between the virtual potential temperature at the two levels occurs. The change in sign of the gradient first occurs at 18:36 UTC (coordinated universal time) on 30 June 2011 and at 18:51 UTC on 1 July 2011. The buoyancy flux (BF) was computed as

$\mathrm{BF}=\frac{g}{T_{\mathrm{v}}} \overline{w^{\prime} \theta_{\mathrm{v}}^{\prime}}$.

Here, $\overline{w^{\prime} \theta_{\mathrm{v}}^{\prime}}$ is the vertical kinematic flux of virtual potential temperature. The lowest sensor $(2.23 \mathrm{~m})$ is used to define when the buoyancy flux ceases. In other words, when there is no more heat coming from the ground being mea-
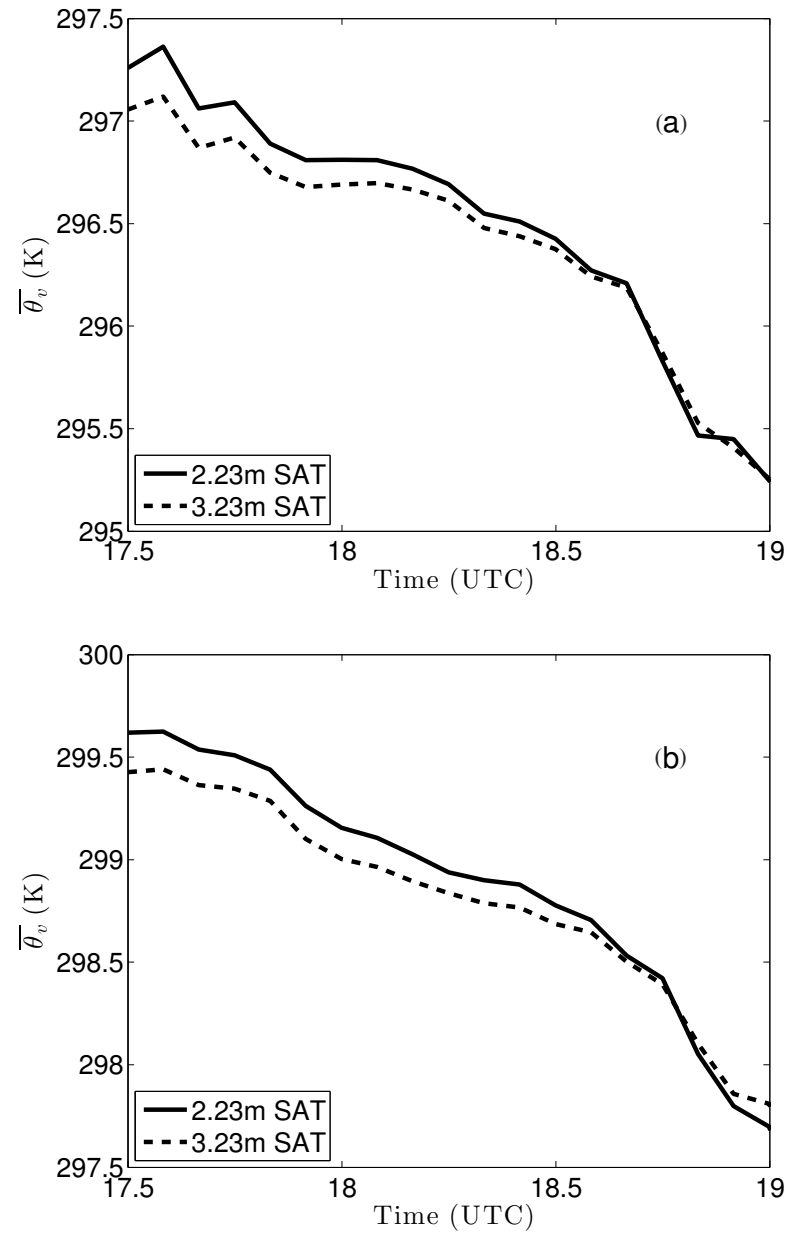

Figure 3. Observed temporal evolution of the virtual potential temperature at $2.23 \mathrm{~m}$ (solid line) and $3.23 \mathrm{~m}$ (dashed line) during the evening transitions on (a) 30 June and (b) 1 July 2011.

sured at that probe. For instance, on 30 June and on 1 July 2011 the lower sensor shows that the flux ceases at approximately 18:18 and 17:54 UTC, respectively. The delay time between when temperature gradient and buoyancy flux pass through zero is then simply the difference between the two times. 


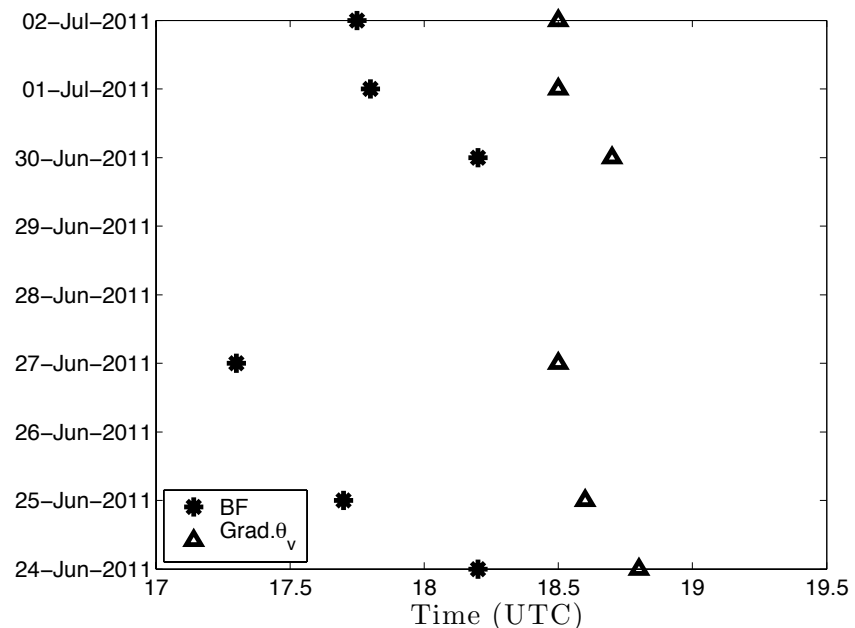

Figure 4. For each IOP, instant when buoyancy flux (bullets) and virtual potential temperature gradient (triangles) change sign.

To develop the theory for the inverse $\mathrm{R}-\mathrm{B}$ problem, the area selected is the lowest surface layer specifically from 2.23 to $8.2 \mathrm{~m}$, which is the area with an evolution closer to the idea proposed by Bénard. First, we calculate the turbulent thermal diffusivity $\left(K_{H}\right)$ and the turbulent viscosity $\left(K_{M}\right)$. These two parameters can be estimated using the following equations.

$$
\begin{aligned}
& K_{H}=\overline{w^{\prime} \theta_{\mathrm{v}}^{\prime}} / \frac{\partial \overline{\theta_{\mathrm{v}}}}{\partial z}, \\
& K_{M}=-u_{*}^{2} / \frac{\partial S}{\partial z},
\end{aligned}
$$

where $u_{*}$ is the friction velocity and $S$ is the mean wind speed. There is relatively little variability in these parameters during the day; therefore, they are estimated by using the maximum buoyancy flux to avoid possible influences of the skin flow close to the afternoon transition and to be consistent during all IOPs.

\section{Results and discussion}

\subsection{Delay time analysis}

Using the procedure described above, the delay time (DT) was computed for all IOPs. The results for all the studied IOPs are summarized in Fig. 4, where the instants when the buoyancy flux and the virtual potential temperature gradient change sign are shown. As is shown in the figure, this delay was present on all days analyzed. The delay varies from around 30 to $80 \mathrm{~min}$. The numerical values for the delay time for all IOPs are given in Table 1.

A possible explanation for the occurrence of this delay can be related to eddy movements associated with warm air plumes that form at the surface. The moment that the buoyancy flux transitions from positive to negative values indicates that no more heat is being introduced to the atmosphere from the ground. Additionally, the upward movement due to warming of the air next to the ground (formation of new thermal plumes) also stops. However, these movements are not instantaneous movements. Quite the opposite, these movements start at the ground, mix through the surface layer and potentially move upward, crossing the entire boundary layer up to the entrainment zone and then descend with the warm air introduced by the overshoots of the eddies in the free atmosphere (i.e., the movements act over an eddy turnover period of time). When the introduction of heat stops $\left(\mathrm{BF}=0 \mathrm{~W} \mathrm{~m}^{-2}\right)$, the last eddy forms and continues to move through the boundary layer. During this eddy turnover time period, the surface layer cools, changing the sign of the temperature gradient. Consequently, the surface layer does not instantaneously respond when the surface flux stops, because the mixing (and heat transfer) continues during one eddy turnover time. This idea has been presented in different studies, for instance by Sorbjan (1997), although it focuses mainly on movements in the entrainment zone and not at the ground. Further, this hypothesis also is compatible with the existence of a neutral layer above the decoupled stable surface layer, where, due to entrainment, turbulence may still exist (Nieuwstadt and Brost, 1986; Grimsdell and Angevine, 2002; Pino et al., 2006).

An analysis of the dimensionless temperature gradient $\left(\phi_{h}\right)$, as described by the Monin-Obukhov similarity theory (MOST), was used to investigate the presence of this delay. Theoretically, the Monin-Obukhov length scale $(L)$ should include the effects associated with synoptic-scale motion (Stull, 1988). $L$ can be used as a scaling parameter to define the convective characteristics of the atmospheric boundary layer. Using this parameter, the effects of buoyancy and mechanical production of turbulence can be compared at a specific altitude. The surface layer scaling parameter $(-z / L)$ provides a metric indicating the strength of the convective conditions during the IOP period leading into the evening transition. We computed $\phi_{h}$ and $-z / L$ as follows:

$\phi_{h}=\frac{k z}{\theta_{\mathrm{v} *}^{S L}} \frac{\partial \theta_{\mathrm{v}}}{\partial z}=\frac{k z u_{*}}{-\overline{w^{\prime} \theta_{\mathrm{v}}^{\prime}}} \frac{\partial \theta_{\mathrm{v}}}{\partial z}$,

$-\frac{z}{L}=\frac{k z g\left(\overline{w^{\prime} \theta_{\mathrm{v}}^{\prime}}\right)_{s}}{\overline{\theta_{\mathrm{v}}} u_{*}^{3}}$.

where $k$ is the von Karman constant, and $z$ is the analysis altitude $(2.23 \mathrm{~m})$.

Figure 5 shows every $5 \mathrm{~min} \phi_{h}$ as a function of $-z / L$ at $2.23 \mathrm{~m}$ for 30 June and 1 July 2011. Clearly, there are points which break away from MOST (indicated by the dashed black line). Specifically, gradient theory fails locally due to the countergradient observations that appear in the plots during near stable conditions. Formally, MOST should be valid in the stable layer. However, during the transition period, one 

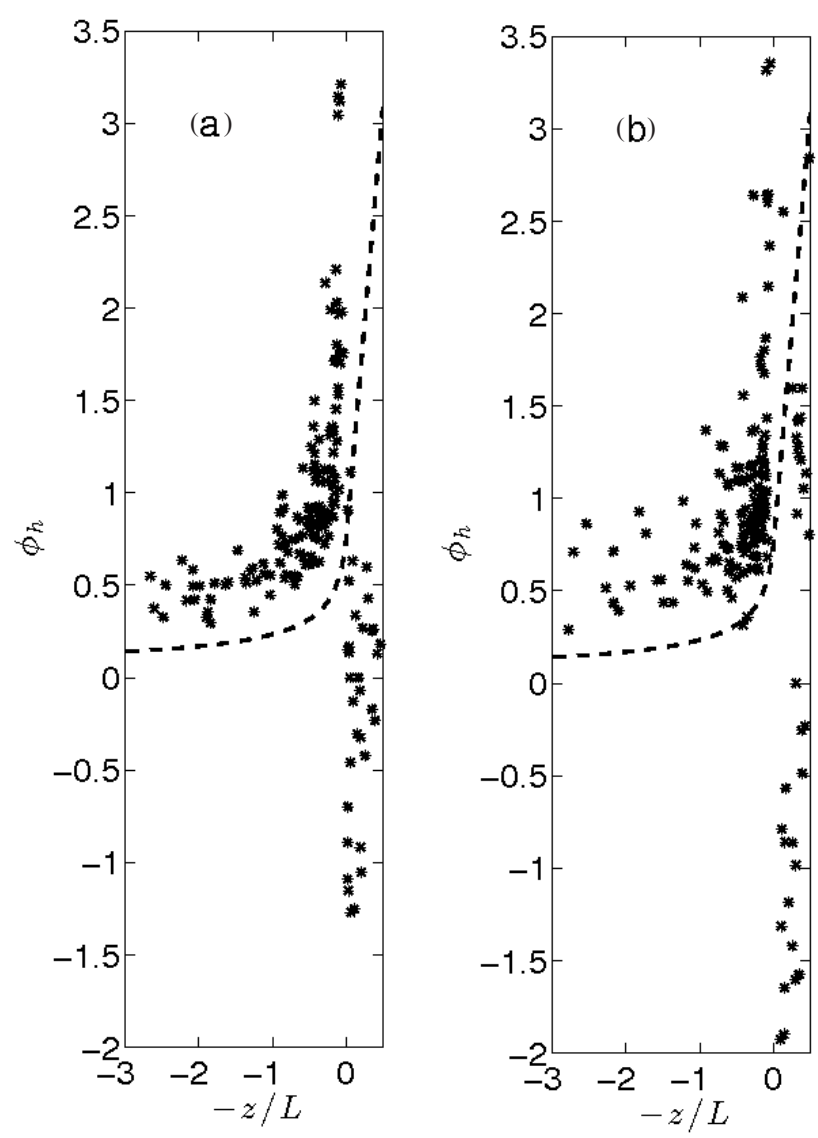

Figure 5. Dimensionless temperature gradient $\left(\phi_{h}\right)$ as a function of $-z / L$ at $2.23 \mathrm{~m}$ on (a) 30 June and (b) 1 July 2011. Dashed line is the approximation of Businger et al. (1971).

can observe that the log surface layer locally disappears close to the ground as there is a decoupling between the old loglayer and the newly forming stable layer, as shown in the transitioning temperature profile in Fig. 2. In the past, this phenomenon was mainly observed for the air-sea boundary layer (Sahlee et al., 2008). However, Smedman et al. (2007) also observed this behavior at a site over land, but for atmospheric conditions that were quite different from our study case. In particular, their case was for strong winds between 7 and $10 \mathrm{~m} \mathrm{~s}^{-1}$ in contrast with BLLAST's calm conditions.

\subsection{Convective time analysis}

To provide support for our delay hypothesis, the convective timescale is analyzed and compared to the delay timescale. The convective timescale can be defined as the approximate time that it takes one eddy to traverse the atmospheric boundary layer. The hypothesis described above should be supported if the value of the delay and the value of the convective time are similar. In other words, the delay exists as a result of the continued movement of the boundary layer due to the last eddy motions generated at the surface.
It should be noted that there is debate in the research community regarding the use of various timescales during the transition period. There is not a general agreement about which scaling time is the best option during the afternoon/evening transition (Nieuwstadt and Brost, 1986; Lothon et al., 2014). However, it will be used to learn more about the theory proposed.

First, the convective timescale $\left(t_{*}\right)$ is computed following Deardorff (1972):

$t_{*}=\frac{z_{i}}{w_{*}}, \quad$ where $w_{*}=\left[\frac{g z_{i}}{\overline{\theta_{\mathrm{v}}}} \overline{w^{\prime} \theta_{\mathrm{v}}^{\prime}}\right]^{\frac{1}{3}}$

being $z_{i}$ the boundary-layer depth. These scales are then computed averaging the 5 min periods just before the buoyancy flux vanishes. The depth of the boundary layer was obtained from the BLLAST campaign's UHF (ultra-high frequency) profiler, which was installed approximately $150 \mathrm{~m}$ away from the $10 \mathrm{~m}$ tower. Specifically, we estimate the height of the ABL from the local maxima of the refractive index structure coefficient (Lothon et al., 2014).

The results from the calculation of the convective timescale for all IOPs are shown in Table 1 and Fig. 6. It is clear that the delay time and the convective time compare better on some IOPs than others. For some IOPs, such as 24 and 30 June 2011, the delay time is nearly the same as the convective time. However, on other days, such as 25 or 27 June, the convective scale and delay time compare quite poorly.

These observed differences between the timescales could be a result of the characteristics of the boundary layer associated with the different IOPs that are not accounted for in the assumptions associated with the convective timescale. In other words, IOPs associated with very convective conditions seem to follow the theory better, while more synoptically forced conditions fail.

\subsection{Monin-Obukhov length analysis}

In contrast to Sect. 4.1, here we computed a characteristic $-z / L$ for each of the IOPs by averaging it over the time period prior to the main afternoon transition (from 12:00 to 16:45 UTC). From the results, we observe that each IOP can be classified as a convective or weakly convective day (see Table 1). The most convective IOPs were 24 and 30 June 2011. These IOPs were also those with a better correlation between the delay time and the convective timescale (see Fig. 6 and Table 1). However, the weaker convective days (i.e., 25 and 27 June 2011) show a larger difference between the delay and convective times (see Table 1). Less-convective days have higher values of $u_{*}$ as a result of increased mechanical turbulence production close to the ground $(2.23 \mathrm{~m})$. On these weakly convective days, the delay time is increased as shear prevents the rapid onset of a stable boundary layer at the surface. 


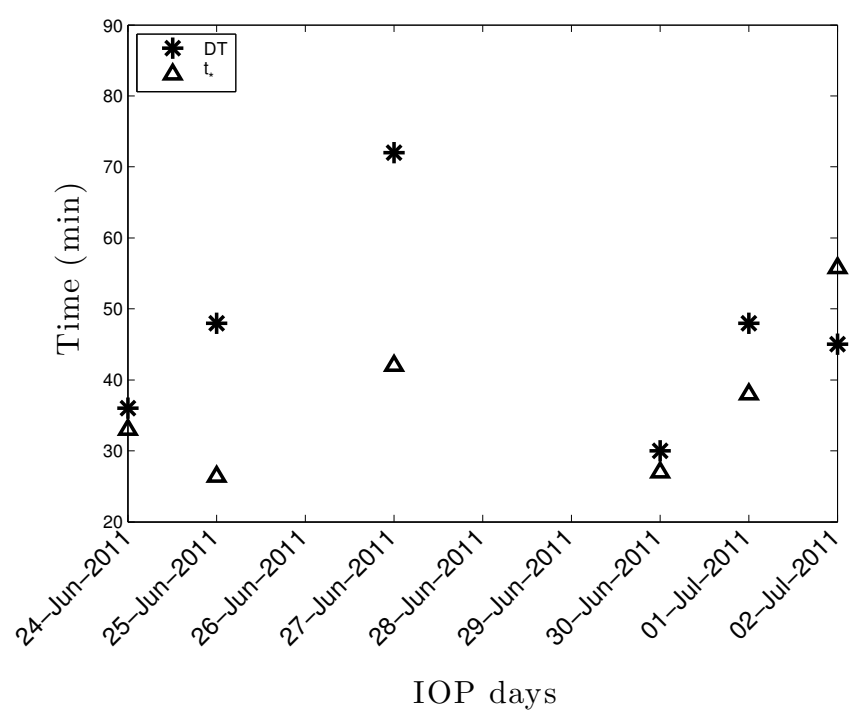

Figure 6. For each IOP, delay (asterisks) and convective (triangles) times.

Figure 7 shows the difference between the two timescales as a function of $-z / L$. Evidently, the BLLAST data indicate an exponentially decreasing relationship between the timescale and the Monin-Obukhov parameter. This relationship is likely to be a function of local effects and should be investigated at other sites to see if a general relationship can be ascertained. Regardless, Fig. 7 shows a potentially site specific method for forecasting the delay time using midday data from a single flux tower.

\subsection{Turbulent Rayleigh number analysis}

The turbulent Rayleigh number $\left(R a_{\text {turb }}\right)$ can be used to explain the behavior of the delay time. It is calculated with Eq. (1) but, instead of using molecular thermal diffusivity $(\kappa)$ and molecular kinematic viscosity $(v)$, we use the turbulent thermal diffusivity (see Eq. 3) and turbulent viscosity (see Eq. 4). Therefore, $R a_{\text {turb }}$ reads

$R a_{\mathrm{turb}}=\frac{g}{\overline{\theta_{\mathrm{v}}}} \frac{\Delta \overline{\theta_{\mathrm{v}}}(\Delta z)^{3}}{K_{H} K_{M}}$,

where $\Delta z$ is the distance between the sensors $(8.2-2.23 \mathrm{~m})$. We select these two sensors because this area has an evolution closer to the idea proposed by Bénard. Turbulent thermal diffusivity and turbulent viscosity could play a role in the initiation or the ceasing of convection. We define the transitional turbulent Rayleigh number $\left(R a_{\mathrm{t}}\right)$ as the value of $R a_{\mathrm{turb}}$ when the buoyancy flux ceases. Figure 8 shows the temporal evolution of buoyancy flux and $R a_{\text {turb }}$ from 17:00 to 20:00 UTC on 30 June and 1 July 2011. As can be observed, $R a_{\text {turb }}$ becomes negative later on 1 July 2011 similarly to the changes in sign of the local virtual potential temperature gradient. For all the analyzed days, BF is negative several tens

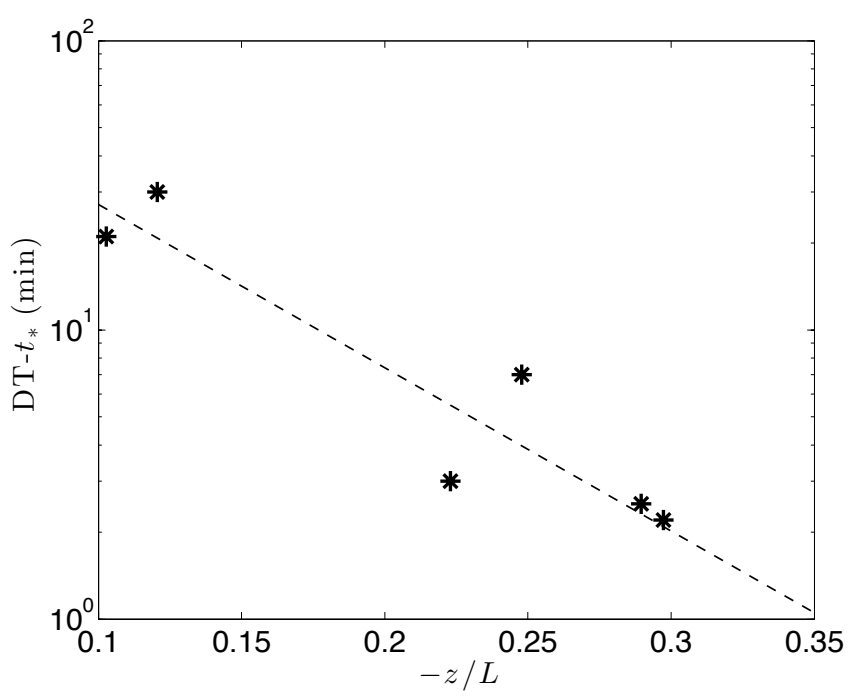

Figure 7. For all the IOPs, difference between the delay and convective times as a function of $-z / L$.

of minutes before $R a_{\mathrm{turb}}$. Table 1 shows this temporal difference and the value of $R a_{\mathrm{t}}$. As can be observed, this temporal difference is clearly related with DT being larger on days with a larger temporal difference between $R a_{\mathrm{t}}$ and $\mathrm{BF}$.

We assume that, on each day, $R a_{\mathrm{t}}$ is in correspondence with the critical Rayleigh number $\left(R a_{\mathrm{cr}}\right)$. It is important to notice that during the early morning of days with large values of $R a_{\mathrm{cr}}$, larger values of buoyancy flux are needed to onset convection. Additionally, during the evening transition on these days, convection stops quickly when the buoyancy flux ceases. By assuming $R a_{\mathrm{t}} \propto R a_{\mathrm{cr}}$, larger values of $R a_{\mathrm{t}}$ have to be observed on these days. Figure 9 shows DT $-t_{*}$ as a function of $R a_{\mathrm{t}}$ for all the studied days. There is an exponentially decreasing relationship between both parameters. IOPs with larger $R a_{\mathrm{t}}$ have a smaller difference between convective and delay times, meaning convection stops quickly. On the contrary, on days with low values of $R a_{\mathrm{t}}$ convection slowed down smoothly, increasing the delay time and consequently $\mathrm{DT}-t_{*}$.

\section{Conclusions}

It has been shown that there is a clear failure of flux gradient theory during the evening transition period as a result of nonlocal processes. Analysis of the data obtained from a $10 \mathrm{~m}$ tower during the BLLAST campaign indicates that a time delay exists between the time when the buoyancy flux ceases and the change in sign of the vertical gradient of the virtual potential temperature. This was the case for all IOPs.

For strong-to-moderate convective days, the delay time is relatively short ( $\sim 30-40 \mathrm{~min})$ and corresponds closely to the timescale associated with the last eddy movements. In other words, it is similar to the convective timescale. However, 

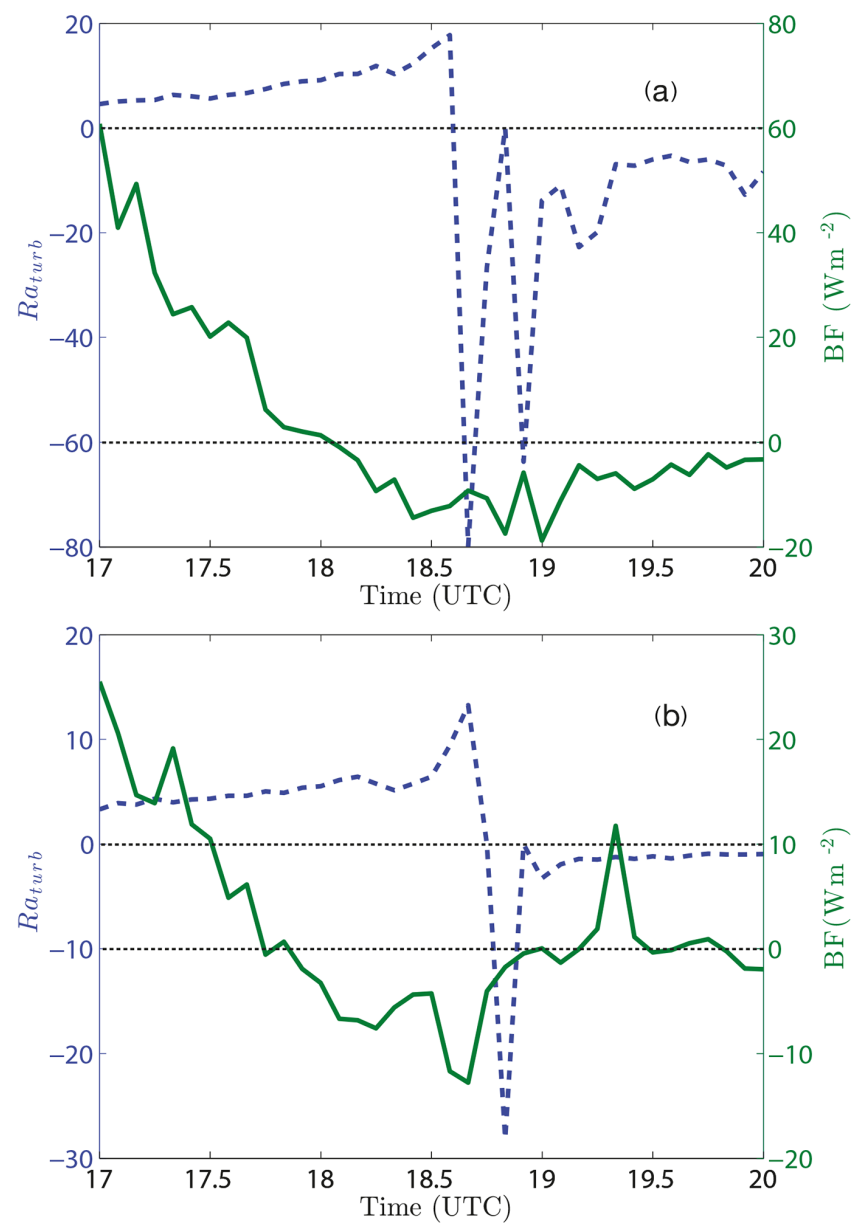

Figure 8. Temporal evolution of buoyancy flux at $2.23 \mathrm{~m}$ (green) and $R a_{\text {turb }}$ (blue) during the evenings of (a) 30 June and (b) 1 July 2011.

when midday convection is weaker, mechanical forces play a much larger role resulting in a larger friction velocity. In these cases, the delay time is larger due to the increase of horizontal turbulence. The data support an exponential relationship between the difference in the delay time and the convective timescale and the Monin-Obukhov parameter $-z / L$. If found to be generalizable, this relationship could be used to help forecast the delay time using midday measurements (for days where large-scale forcings change slowly).

Finally, we defined a transitional turbulent Rayleigh number $\left(R a_{\mathrm{t}}\right)$ associated with the buoyancy flux cease. We observe that higher values of $R a_{\mathrm{t}}$ are related with a faster decay of the convection. Otherwise, turbulent viscosity and thermal diffusivity help to slow down the last eddy movement and increase the delay time when we observe low values of $R a_{\mathrm{t}}$.

In order to generalize the observations described in this paper, future work should investigate the delay hypothesis over additional convective days and various types of surfaces. To accomplish this, it is recommend that future observational campaigns include sufficient temperature and flux measure-

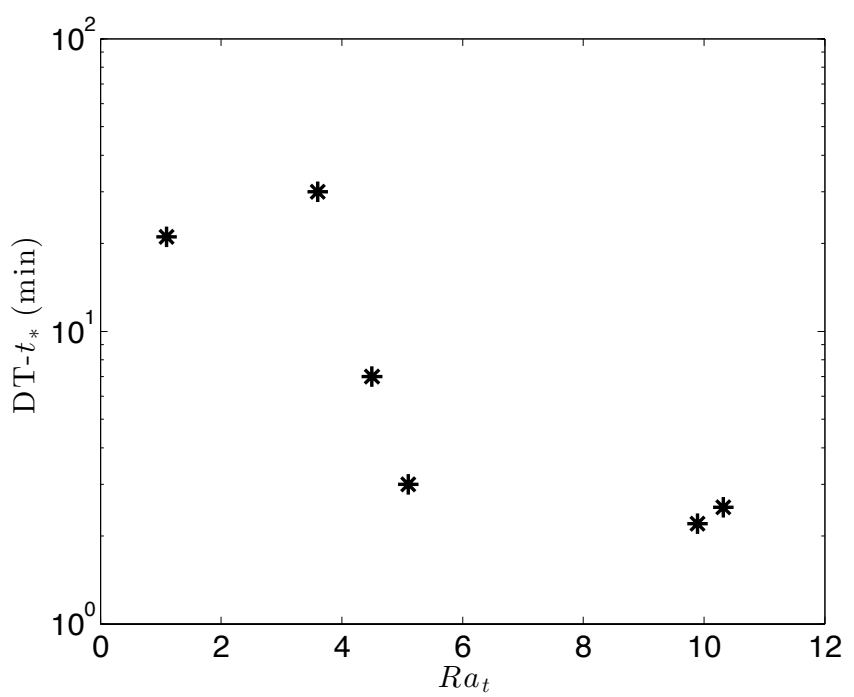

Figure 9. For all the IOPs, difference between the delay and convective times as a function of $R a_{\mathrm{t}}$.

ments near the ground to sufficiently resolve the countergradient processes.

Acknowledgements. The authors wish to thank Andrey Grachev for his thoughts and advice on the topic presented and Jens Bange for his interesting comments during the revision process.

This project was performed under the Spanish MINECO projects CGL2009-08609, CGL2012-37416-C04-03 and the European POCTEFA 720 FluxPyr program. The stage at the University of Utah was performed under the Spanish MINECO project EEBBI-12-05228. This work was partially supported by the United States Office of Naval Research, award no. N00014-11-1-0709.

The BLLAST field experiment was made possible thanks to the contribution of several institutions and their support: INSU-CNRS (Institut National des Sciences de l'Univers, Centre National de la Recherche Scientifique, LEFE-IDAO program), Météo-France, Observatoire Midi-Pirénées (University of Toulouse), EUFAR (EUropean Facility for Airborne Research) and COST ES0802 (European Cooperation in Science and Technology). The field experiment would not have occurred without the contribution of all participating European and American research groups, all of which contributed significantly. The BLLAST field experiment was hosted by the instrumented site of Centre de Recherches Atmosphériques, Lannemezan, France (Observatoire Midi-Pirénées, Laboratoire d'Aérologie). BLLAST data are managed by SEDOO, from Observatoire Midi-Pirénées.

Edited by: R. J. Beare

\section{References}

Angevine, W. M.: Transitional, entraining, cloudy, and coastal boundary layers, Acta Geophys., 56, 2-20, 2007.

Beare, R. J., Edwards, J. M., and Lapworth, A. J.: Simulation of the observed evening transition and nocturnal boundary layers: large-eddy modelling, Q. J. R. Meteorol. Soc., 132, 61-80, 2006. 
Businger, J. A., Wyngaard, J. C., Izumi, Y., and Bradley, E. F.: FluxProfile Relationships in the Atmospheric Surface Layer, J. Atmos. Sci., 28, 181-189, 1971.

Chapra, S. C. and Canale, R. P.: Numerical Methods for Engineers, Boston, McGraw-Hill Companies, 3 edn., 1998.

Cole, G. S. and Fernando, H. J. S.: Some aspects of the decay of convective turbulence, Fluid. Dyn. Res., 23, 161-176, 1998.

Darbieu, C., Lohou, F., Lothon, M., Couvreux, F., Pino, D., Durand, P., Blay-Carreras, E., and Vilà-Guerau de Arellano, J.: Evolution of the turbulence during the afternoon transition of the convective boundary layer: a spectral analysis, J. 21st Symposium on Boundary Layer and Turbulence, 8-13 June 2014, Leeds (UK), 2014.

Deardorff, J.: Numerical Investigation of Neutral and Unstable Planetary Boundary Layers, J. Atmos. Sci., 7, 91-115, 1972.

Edwards, J. M., Beare, R. J., and Lapworth, A. J.: Simulation of the observed evening transition and nocturnal boundary layers: Single-column modelling, Q. J. Roy. Meteorol. Soc., 132, 6180, 2006.

Fedorovich, E., Nieuwstadt, F. T. M., and Kaiser, R.: Numerical and laboratory study of horizontally evolving convective boundary layer. Part II: Effects of elevated wind shear and surface roughness, J. Atmos. Sci., 58, 546-560, 2001.

Franchitto, S. H. and Rao, V. B.: The correlation between temperature gradient and eddy heat flux in the northern and southern hemispheres, J. Meteorol. Soc. Jpn. Ser. II, 81, 163-168, 2003.

Ghan, S. J.: Modelling the synoptic scale relationship between eddy heat flux and the meridional temperature gradient, Massachusetts Institute of Technology (MIT), Cambridge, Massachusetts, USA, 1981.

Grimsdell, A. W. and Angevine, W. M.: Observations of the afternoon transition of the convective boundary layer, J. Appl. Meteorol., 41, 3-11, 2002.

Haeffelin, M., Angelini, F., Morille, Y., Martucci, G., Frey, S., Gobbi, G. P., Lolli, S., O’Dowd, C. D., Sauvage, L., XuerefRémy, I., Wastine, B., and Feist, D. G.: Evaluation of mixingheight retrievals from automatic profiling lidars and ceilometers in view of future integrated networks in europe, Bound.-Lay. Meteorol., 143, 49-75, 2012.

Holtslag, A. A. M. and Moeng, C.: Eddy diffusivity and countergradient transport in the convective atmospheric boundary layer, J. Atmos. Sci., 48, 1690-1698, 1991.

Holtslag, A. A. M. and Moeng, C.: Local versus nonlocal boundarylayer diffusion in a global climate model, J. Climate, 6, 18251842, 1991.

Kundu, P. J. and Cohen, I. M.: Fluid Mechanics, Academic Press, Waltham (MA), USA, 904 pp., 2010.

Lothon, M. and Lenschow, D.: Studying the afternoon transition of the planetary boundary layer, Eos Trans. AGU, 91, 253-260, 2010.

Lothon, M., Lohou, F., Pino, D., Couvreux, F., Pardyjak, E. R., Reuder, J., Vilà-Guerau de Arellano, J., Durand, P., Hartogensis, O., Legain, D., Augustin, P., Gioli, B., Faloona, I., Yagüe, C., Alexander, D. C., Angevine, W. M., Bargain, E., Barrié, J., Bazile, E., Bezombes, Y., Blay-Carreras, E., van de Boer, A., Boichard, J. L., Bourdon, A., Butet, A., Campistron, B., de Coster, O., Cuxart, J., Dabas, A., Darbieu, C., Deboudt, K., Delbarre, H., Derrien, S., Flament, P., Fourmentin, M., Garai, A., Gibert, F., Graf, A., Groebner, J., Guichard, F., Jimenez Cortes,
M. A., Jonassen, M., van den Kroonenberg, A., Lenschow, D. H., Magliulo, V., Martin, S., Martinez, D., Mastrorillo, L., Moene, A. F., Molinos, F., Moulin, E., Pietersen, H. P., Piguet, B., Pique, E., Román-Cascón, C., Rufin-Soler, C., Saïd, F., Sastre-Marugán, M., Seity, Y., Steeneveld, G. J., Toscano, P., Traullé, O., Tzanos, D., Wacker, S., Wildmann, N., and Zaldei, A.: The BLLAST field experiment: Boundary-Layer Late Afternoon and Sunset Turbulence, Atmos. Chem. Phys. Discuss., 14, 10789-10852, doi:10.5194/acpd-14-10789-2014, 2014.

Mahrt, L.: Nocturnal boundary-layer regimes, Bound.-Lay. Meteorol., 88, 255-278, 1998.

Moeng, C.-H. and Sullivan, P. P.: A comparison of shear- and buoyancy-driven planetary boundary layer flows, J. Atmos. Sci., 51, 999-1022, 1994.

Nadeau, D. F., Pardyjak, E. R., Higgins, C. W., Fernando, H. J. S., and Parlange, M. B.: A simple model for the afternoon and early evening decay of convective turbulence over different land surfaces, Bound.-Lay. Meteorol., 141, 301-324, 2011.

Nieuwstadt, F. T. M.: The turbulent structure of the stable, nocturnal boundary layer, J. Atmos. Sci., 41, 2202-2216, 1984.

Nieuwstadt, F. T. M. and Brost, R. A.: The decay of convective turbulence, J. Atmos. Sci., 43, 532-546, 1986.

Pino, D., Vilà-Guerau de Arellano, J., and Duynkerke, P. G.: The contribution of shear to the evolution of a convective boundary layer, J. Atmos. Sci., 60, 1913-1926, 2003.

Pino, D., Jonker, H. J. J., Vilà-Guerau de Arellano, J., and Dosio, A.: Role of shear and the inversion strength during sunset turbulence over land: Characteristic length scales, Bound.-Lay. Meteorol., 121, 537-556, 2006.

Sahlée, E., Smedman, A., Rutgersson, A., and Högström, U.: Influence of a new turbulence regime on the global air-sea heat fluxes, J. Climate, 121, 5925-5941, 2007.

Smedman, A., Högström, U., Hunt, J. C. R., and Sahlée, E.: Heat/mass transfer in the slightly unstable atmospheric surface layer, Q. J. Roy. Meteorol. Soc., 133, 37-51, 2007.

Sorbjan, Z.: Effects caused by varying the strength of the capping inversion based on a large eddy simulation model of the shearfree convective boundary layer, J. Atmos. Sci., 53, 2015-2024, 1996.

Sorbjan, Z.: Decay of convective turbulence revisited, Bound.-Lay. Meteorol., 82, 503-517, 1997.

Stull, R. B.: An introduction to boundary layer meteorology, D. Reidel Publ. Comp., Dordrecht, The Netherlands, 670 pp., 1988.

Sullivan, P. P., Moeng, C.-H., Stevens, B., Lenschow, D. H., and Mayor, S. D.: Structure of the entrainment zone capping the convective atmospheric boundary layer, J. Atmos. Sci., 55, 3042 3064, 1998.

Van Dijk, A., Moene, A. F., and De Bruin, H. A. R.: The principles of surface flux physics: theory, practice and description of the ECPACK library, Internal Report 2004/1, Meteorology and Air Quality Group, Wageningen University, Wageningen, The Netherlands, 99 pp., 2004.

van Driel, R. and Jonker, H. J. J.: Convective Boundary Layers Driven by Nonstationary Surface Heat Fluxes, J. Atmos. Sci., 68, 727-738, 2011. 